\title{
Eating and inflicting pain out of boredom
}

Citation for published version (APA):

Havermans, R. C., Vancleef, L., Kalamatianos, A., \& Nederkoorn, C. (2015). Eating and inflicting pain out of boredom. Appetite, 85, 52-57. https://doi.org/10.1016/j.appet.2014.11.007

Document status and date:

Published: 01/01/2015

DOI:

10.1016/j.appet.2014.11.007

Document Version:

Publisher's PDF, also known as Version of record

Document license:

Taverne

Please check the document version of this publication:

- A submitted manuscript is the version of the article upon submission and before peer-review. There can be important differences between the submitted version and the official published version of record.

People interested in the research are advised to contact the author for the final version of the publication, or visit the DOI to the publisher's website.

- The final author version and the galley proof are versions of the publication after peer review.

- The final published version features the final layout of the paper including the volume, issue and page numbers.

Link to publication

\footnotetext{
General rights rights.

- You may freely distribute the URL identifying the publication in the public portal. please follow below link for the End User Agreement:

www.umlib.nl/taverne-license

Take down policy

If you believe that this document breaches copyright please contact us at:

repository@maastrichtuniversity.nl

providing details and we will investigate your claim.
}

Copyright and moral rights for the publications made accessible in the public portal are retained by the authors and/or other copyright owners and it is a condition of accessing publications that users recognise and abide by the legal requirements associated with these

- Users may download and print one copy of any publication from the public portal for the purpose of private study or research.

- You may not further distribute the material or use it for any profit-making activity or commercial gain

If the publication is distributed under the terms of Article $25 \mathrm{fa}$ of the Dutch Copyright Act, indicated by the "Taverne" license above, 
Research report

\title{
Eating and inflicting pain out of boredom
}

\author{
Remco C. Havermans, Linda Vancleef, Antonis Kalamatianos, Chantal Nederkoorn * \\ Faculty of Psychology and Neuroscience, Clinical Psychological Science, Maastricht University, PO Box 616, 6200 MD Maastricht, The Netherlands
}

\section{A R T I C L E I N F O}

\section{Article history:}

Received 11 July 2014

Received in revised form 29 September

2014

Accepted 6 November 2014

Available online 11 November 2014

\section{Keywords:}

Emotional eating

Boredom

Self-inflicting pain

Self-injury

NSSI

Negative reinforcement

\begin{abstract}
A B S T R A C $T$
In the present study it was investigated whether boredom promotes eating and if so, whether this effect likely reflects an increased drive for rewarding stimulation (positive reinforcement) or more plainly the drive to escape boredom (negative reinforcement). In the latter case, the valence of the stimulation should not matter and people might even be willing to look for negative stimulation, for instance to hurt oneself, just to escape boredom. In two parallel experiments, it was tested whether induced boredom promotes the consumption of chocolate (Experiment 1) and whether participants likewise are more inclined to self-administer electrocutaneous stimuli (Experiment 2). In both experiments, a total of 30 participants attended two separate sessions watching a documentary for $1 \mathrm{~h}$ (neutral condition) and a monotonous repetition of a single clip from the same documentary for $1 \mathrm{~h}$ (boring condition), in balanced order. During Experiment 1, participants had free access to M\&Ms and during Experiment 2 participants could freely self-administer brief electrical shocks. It was found that participants ate more M\&Ms when bored but also that they more readily self-administered electrical shocks when bored. It is concluded that eating when bored is not driven by an increased desire for satisfying incentive stimulation, but mainly by the drive to escape monotony.
\end{abstract}

(c) 2014 Elsevier Ltd. All rights reserved.

\section{Introduction}

Recently, Eastwood, Frischen, Fenske, and Smilek (2012) stated that boredom can be conceptualized as the aversive experience of not being able to engage in a satisfying activity. "Boredom is the experience of being disengaged and stuck in an endless dissatisfying present" (p. 484). This is not a trivial experience. Boredom (or boredom proneness) has been linked to serious psychopathology such as depression and anxiety (see e.g., Sommers \& Vodanovich, 2000). It is even associated with death; self-reports of experiencing boredom frequently predicted mortality rate (Britton \& Shipley, 2010).

Boredom has also been associated with food cravings and overeating (Hill, Weaver, \& Blundell, 1991; Stickney \& Miltenberger, 1999). In a study by Koball, Meers, Storfer-Isser, Domoff, and MusherEizenman (2012), 139 participants were asked to describe what they typically do when experiencing a particular emotion with a given intensity. The participants frequently reported "eating" when specifically feeling bored.

To our knowledge, there is only one experimental study demonstrating that boredom is not just associated with food intake, but also directly promotes eating. In this experiment by Abramson and Stinson (1977), 60 participating women were given a writing task. For half of the women the task comprised writing creative stories

\footnotetext{
* Corresponding author.

E-mail address: c.nederkoorn@maastrichtuniversity.nl (C. Nederkoorn).
}

inspired by pictures of different scenes. For the remaining half of the participants, the task involved writing the letters "cd" over and over again for nearly half an hour. All participants were allowed to eat from a bowl of Wheat Thin crackers during their writing. It was found that the repetitive writing task elicited self-reported boredom, as one would expect. More importantly, this bored group of women ate nearly twice as many crackers.

As noted by Eastwood et al. (2012), the cause for boredom is typically attributed externally. One feels bored because a task, or a given situation is boring. A boring task is a task that typically requires little cognitive effort and is repetitive. Monotony renders the experience highly predictable and this is universally disliked (O'Hanlon, 1981) and can even be viewed as an important stressor (Thackray, 1981). Indeed, "boredom occurs when stimulation is subjectively construed as monotonous" (Hill \& Perkins, 1985, p. 237). Furthermore, such monotony-induced boredom is associated with a strong sense of frustration (see also Hill \& Perkins).

According to the general definition of boredom proposed by Eastwood et al. (2012), any monotonous stimulation would induce boredom and hence create the desire for engaging in other more satisfying activities. It is not quite clear what constitutes 'satisfaction' though. Does boredom induce a desire for especially satisfying, rewarding stimuli such as food? This would explain the finding by Abramson and Stinson (1977) that people tend to overeat when bored. There is however an alternative explanation for this finding. O'Hanlon (1981) argued that boredom simply motivates to seek a change in stimulation. Whether that change provides for any meaningful, satisfying or otherwise rewarding stimulation does not matter 
as long as it disrupts any monotony. This is a clear negative reinforcement perspective on the motivating property of boredom. Boredom is an aversive state brought about by monotonous stimulation. Any act that changes stimulation, be it rewarding or even aversive, can at least briefly alleviate boredom and is negatively reinforced. So if one has the opportunity to eat when bored, one is likely to eat much more. This sounds sensible, but this perspective counterintuitively implies that when bored one might even go so far as to hurt oneself just to escape monotony.

In the present study, we ran two parallel experiments in an attempt to replicate Abramson and Stinson's basic finding that inducing boredom through a monotonous task promotes eating chocolate, which is a pleasurable stimulus (Experiment 1 ), and to examine whether people under the same boring circumstances might also be motivated to self-administer negative stimulation, namely electroshocks (Experiment 2). A secondary aim of this study was to examine whether any boredom-effect on eating or electroshocking behavior is moderated by individual differences in the traits boredom proneness and sensation seeking.

\section{General method}

\section{Participants}

The study was reviewed and approved by a local research ethics committee of the Faculty of Psychology and Neuroscience of Maastricht University. With approval by this committee the responsible investigators commit themselves to treat the participants in line with the ethical principles regarding human experimentation as stated in the Declaration of Helsinki.

A total of 60 participants ( 49 women, 11 men; $M$ age $=24.4$ years) were recruited at Maastricht University over a period of 10 weeks. They were invited to participate in an experiment that was announced as a study concerning personality and visual stimuli. They were randomly assigned to take part in either Experiment 1 or Experiment 2 in exchange for a 20 euro voucher or study credits.

\section{Procedure, materials, and design}

In the two within-subjects experiments reported here, we used the same procedure to induce boredom in the participants. Participants were tested individually and came to the lab on two days (separated by 2 workdays). On each day the participant watched a segment of the 95 min documentary In Search of Memory (Seeger, 2008). This documentary depicts the intriguing life and research on memory of the then 79-year-old Nobel laureate and neuroscientist Eric Kandel.

On one of the two days, the participants watched the first $60 \mathrm{~min}$ of the documentary (neutral condition). After the first hour of the documentary, there is a scene in which Kandel plays a game of indoor tennis with one of his friends. On the other day, the participants were instructed to watch this $85 \mathrm{~s}$ scene over and over again for 60 min (boring condition). For both experiments, the order of the sessions (boring versus neutral) was counterbalanced between participants.

During both 1-h sessions, the participants could either eat chocolate M\&Ms (Experiment 1 ) or self-administer electrical stimuli (Experiment 2). Before watching the 60 min segment (monotonous or not), the participant was instructed to remove any Zeitgebers (e.g., watch, mobile phone, MP3 player, et cetera), as not being able to readily tell time was thought to add to the experience of boredom (Danckert \& Allman, 2005). The experimenter carefully monitored further adherence to the instructions (i.e. "watch the film clip").

Before and after watching the 60 min segment, the participants were asked to rate a range of different feelings on visual analog scales (VAS) ranging from 0 ('not at all') to 10 ('extremely').
Participants thus rated their momentary hunger and indicated how bored, tired, and frustrated they felt. Further, at the end of each session, the participants rated how boring, monotonous, and enjoyable they found the film segment.

At the end of the second session, all participants were asked to fill out the Boredom Proneness Scale (BPS; Farmer \& Sundberg, 1986). We used the translated and validated Dutch BPS (Zondag, 2007). Further, the participants filled out the validated Dutch version of the Sensation Seeking Scale (SSS; Zuckerman, Kolin, Price, \& Zoob, 1964; Zuckerman, 2007), translated and developed by Feij, van Zuilen, and Gazendam (1982).

\section{Data analysis}

For both experiments, we first tested whether the participants indeed became more bored, tired, and frustrated with having to watch the monotonous film segment by conducting three separate repeated measures two-way ANOVAs comparing the mean VAS ratings for (a) boredom, (b) fatigue and (c) frustration before versus after (Time) watching either the monotonous or the non-monotonous 60 min film segment (Session). Secondly, we tested (with separate paired samples t-tests) whether the participants rated the monotonous film segment as (a) more boring, (b) more monotonous, and (c) less enjoyable than the non-monotonous film segment.

For Experiment 1, we then assessed whether monotonous stimulation promotes eating. To explore the possibility that boredom proneness and/or sensation seeking moderate this potential effect we conducted a one-way (Session: monotonous film segment versus non-monotonous film segment) repeated measures ANCOVA with weight of M\&Ms consumed (in grams) as the dependent variable and the total Dutch BPS and SSS scores entered together as covariates. Both the main effects of the covariates and the interaction effects with condition were tested.

For Experiment 2, the main analysis also comprised a repeated measures one-way (Session: monotonous film segment versus nonmonotonous film segment) ANCOVA with the frequency of selfadministered electrocutaneous stimuli as the dependent variable and again the total Dutch BPS and SSS scores as covariates. We conducted the same analysis with highest self-selected shock intensity as the dependent variable.

\section{Experiment 1}

This experiment considered whether monotonous stimulation induces boredom and hence promotes eating as has been shown in a previous study by Abramson and Stinson (1977). We examined this question by placing a candy dispenser filled with chocolate M\&Ms within reach on the table directly next to the screen displaying the film segment from In Search of Memory. Note that the activity is the same across the 2 sessions, that is, watching a $60 \mathrm{~min}$ film segment. We hypothesized that when that activity comprises monotonous stimulation (i.e., the looped 85 s scene of Kandel playing tennis) participants would be more inclined to eat from the chocolate M\&Ms.

\section{Method}

Thirty participants of the sample of 60 recruited participants were randomly assigned to take part in Experiment 1 ( 22 women, 8 men; $M$ age $=24.8$ years $)$. Upon arrival for the first session, the participant was seated at a table and was provided written information concerning the experiment. After signing a consent form, the participant was instructed to watch the film segment for that particular session and was told that s/he could take as many chocolate M\&Ms from the candy dispenser (Magic Candy Dispenser; JLR Gear, Hong Kong) as s/he liked. As stated above, the experimenter monitored 


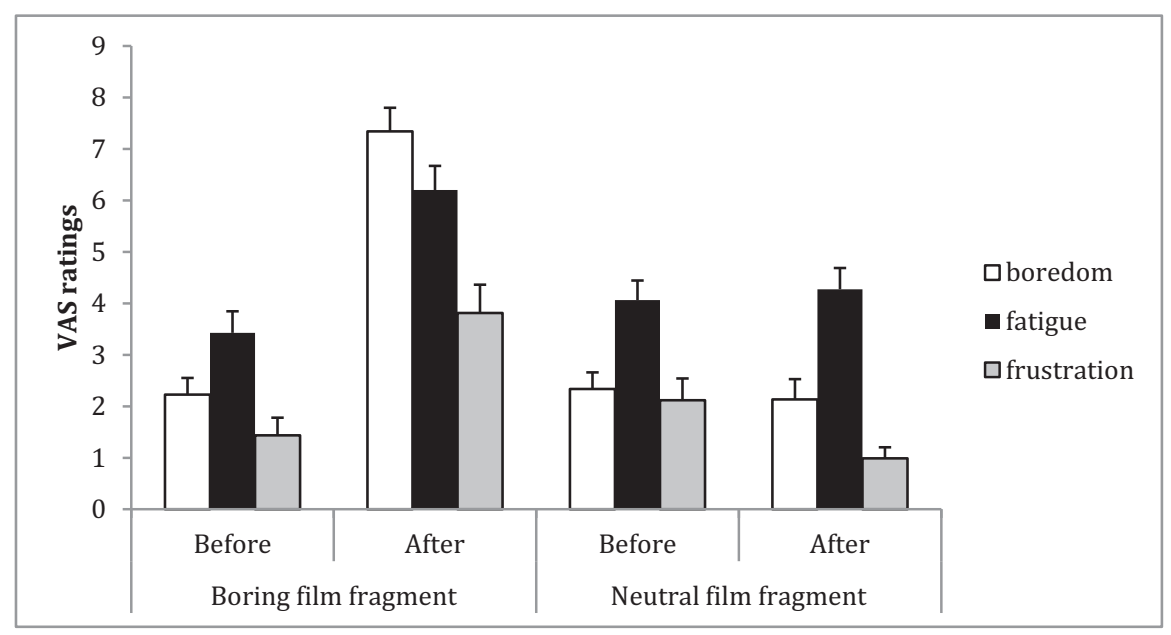

Fig. 1. Mean ratings of boredom, fatigue and frustration (+SEM) before and after viewing the boring versus neutral 60 min film segment of experiment 1.

adherence to the instructions in an adjacent control room and by weighing the dispenser before and after watching the documentary segment with a precision balance (Salter Brecknell ESA-3000, capable of weighing to the nearest $.05 \mathrm{~g}$; Smethwick, UK) we determined the amount of M\&Ms consumed.

\section{Results and discussion}

We first examined whether participants would come to feel more bored, tired and frustrated when watching the boring film segment. This proved to be the case, as shown in Fig. 1.

For the boredom ratings, a significant interaction between Time (before vs. after) and Session (boring vs. neutral film segment) was found, $F(1,29)=62.31, p<.001, \eta^{2}$ partial $=.68$. The participants reported more boredom from before to after watching the boring film segment, $F(1,29)=122.14, p<.001, \eta^{2}$ partial $=.81$, and no change in boredom when watching the neutral film segment, $F(1,29)=.20$, $p=.66$. The same interaction was found for the fatigue ratings $(F[1$, $29]=12.62, p=.001, \eta^{2}$ partial $\left.=.30\right)$ with an increase in feeling tired when having to watch the boring film segment, $F(1,29)=28.95$, $p<.001, \eta^{2}$ partial $=.50$, relative to the non-monotonous film segment $F(1,29)=.30, p=.59$. Further, frustration ratings too showed the same interaction, $F(1,29)=33.51, p<.001, \eta^{2}$ partial $=.54$. Frustration increased with having to watch the boring film segment, $F(1,29)=20.64, p<.001, \eta^{2}$ partial $=.42$, and decreased when viewing the neutral film segment, $\left.F(1,29)=5.24, p<.05, \eta_{\text {partial }}^{2}=.15\right)$.

In line with the above findings, the participants rated the boring film segment as significantly more boring $(t[29]=14.37, p<.001)$, more monotonous $(t[29]=19.57, p<.001)$, and less enjoyable $(t[29]=11.28, p<.001)$ than the neutral film segment. These results indicate that our method of manipulating boredom was adequate. The participants did not differ in their momentary hunger before the two sessions ( $M_{\text {boring }}=3.11$ vs. $M_{\text {neutral }}=3.49, \mathrm{t}[29]=.8, p=.42$ ).

Figure 2 depicts the mean amount of M\&Ms consumed (in $\mathrm{g}$; + SEM) by the participants during viewing the monotonous versus the non-monotonous 60 min film segment. The results of primary interest indicate that induced boredom indeed promotes consumption of chocolate M\&Ms, as was hypothesized. Very similar to the original finding of Abramson and Stinson (1977), the current participants ate approximately twice as much when exposed to boring film fragment relative to the session in which the participants watched the neutral film segment, $F(1,27)=32.96, p<.001$, $\eta_{\text {partial }}^{2}=.55$. No interactions with the added covariates (i.e., BPS score, $M=3.1, S D=.77$ and the SSS score, $M=3.03, S D=.45$ ) were found, both $F s<1$. Both covariates also did not affect how many M\&Ms the participants ate, largest $F(1,27)=1.66$.

In short, having to watch a short clip on repeat for $60 \mathrm{~min}$ can induce a strong sense of boredom and this significantly promotes eating. This finding replicates prior results by Abramson and Stinson (1977). But the question arises whether this clear effect of boredom on eating is the likely result of the participants actively seeking some kind of satisfying, rewarding stimulation to overcome their negative state. Eating food, especially palatable food, is rewarding and has been found to increase mood (Macht \& Dettmer, 2006; Macht \& Mueller, 2007). Indeed, research showed that other negative states, like sadness or stress, increase intake of hedonic foods (Garg, Wansink, \& Inman, 2007), although findings in the literature are not consistent and individual differences, like emotional eating, are probably moderating the effect of mood on food intake (Macht, 2008).

Alternatively, the increased food intake after boredom could be the result of the participants trying to disrupt the tedium of watching the same film clip over and over again with whatever means possible. This is in line with the theory that binge eating might be motivated by a desire to escape from emotional distress (Heatherton \& Baumeister, 1991). Also according to this theory, eating can be negatively reinforced by reduction of negative emotions (Williamson, White, York-Crowe, \& Stewart, 2004).

If the increased food intake in Experiment 1 served the function of disrupting the negative state of boredom, this implies that

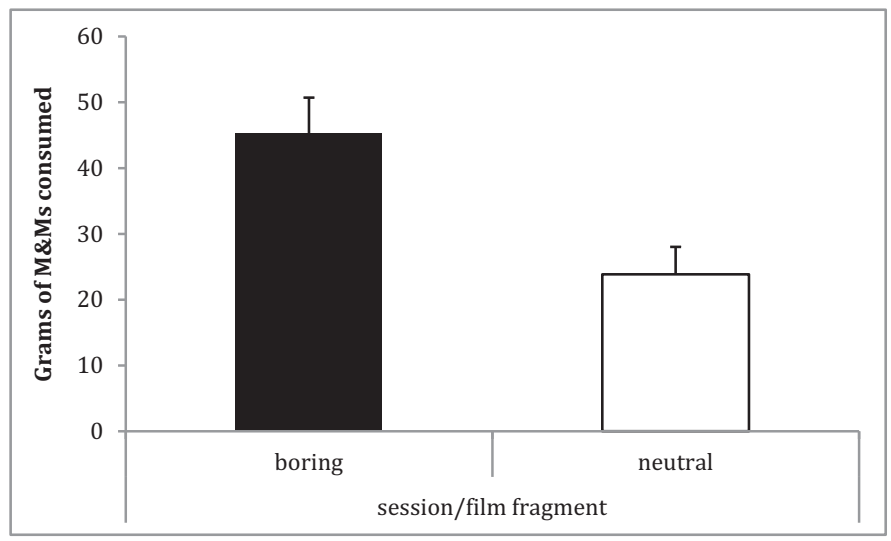

Fig. 2. Mean consumption of M\&Ms (in $g ;+$ SEM) during viewing of the boring versus neutral $60 \mathrm{~min}$ film segment. 
the valence of the stimulation is of less importance and people might even be willing to (potentially) hurt themselves to escape monotony.

\section{Experiment 2}

In this second experiment, we examined whether monotonous stimulation promotes the desire to disrupt monotony even if that disruption would mean having to self administer electrical stimulation.

\section{Method}

The remaining 30 participants of the initial sample of 60 candidates ( 27 women, 3 men; $M$ age $=23.9$ ) were assigned to take part in Experiment 2. Upon arrival for the first session, the participant was seated at a table and was provided written information concerning the experiment. After signing a consent form, two 8-mm electrodes (filled with hypertonic gel; spaced $1 \mathrm{~cm}$ apart) were attached to the inside of the non-dominant lower arm. The electrodes connected the participant to a bipolar constant current stimulator (DS5, Digitimer, Hertfordshire, UK). The participant sat in front of an IBM compatible desktop computer that was connected to two 19-inch computer screens (one for the participant and one for the experimenter in the adjacent experimenter control room).

The participant was advised orally and in writing that s/he could self-administer an electrocutaneous shock by first selecting on the computer the intensity of the shock (varying between 1 and $20 \mathrm{~mA}$ ) and then pressing the space bar. Note that participants were not familiarized with the different shock intensities. At any instance they could choose the intensity they liked. They were informed that, if they choose to administer a shock, they should start with $1 \mathrm{~mA}$ shock, which produces a mild sensation and thereafter gradually increase the intensity, to avoid unexpected painful stimulation. When having selected a certain shock intensity, an electrical stimulus (duration: $300 \mathrm{~ms}$; sinus wave: $50 \mathrm{~Hz}$ ) of the selected intensity would be delivered $1 \mathrm{~s}$ after the participant pressed the space bar. The computer program for self-administering and registering the delivery of electrocutaneous stimulation was programmed in Presentation (Neurobehavioral Systems, Inc., Albany, CA, USA).
The procedure for this experiment was similar to Experiment 1; however, participants had the option to administer electrocutaneous stimulation instead of eating M\&Ms.

\section{Results and discussion}

In the same way as for Experiment 1, we first analyzed whether the boring versus the neutral film segment induced boredom, fatigue and frustration. This proved to be the case, as shown in Fig. 3.

For the boring ratings, a significant Session $\times$ Time interaction effect was found, $F(1,29)=21.80, p<.001, \eta^{2}$ partial $=.43$. There was a significant increase in rated boredom in case of watching the boring film segment, $F(1,29)=53.39, p<.001, \eta^{2}$ partial $=.65$, and not when viewing the neutral film segment, $F(1,29)=2.88, p=.10$. Both film segments induced fatigue and this main effect was significant $(F[1$, $29]=27.57, p<.001, \eta^{2}$ partial $=.49$ ), but the interaction effect was not $(F[1,29]=0.64, p=.43)$. Finally, there was a significant interaction between Session and Time for the frustration ratings, $F(1,29)=21.51$, $p=.002, \eta^{2}$ partial $=.28$. The boring film segment promoted frustration, $F(1,29)=8.7, p<.001, \eta^{2}$ partial $=.23$, whereas frustration did not change with viewing the neutral film segment $F(1,29)=1.3, p=.26$. As in Experiment 1, the participants found the boring film segment to be significantly more boring $(t[29]=9.72, p<.001)$, more monotonous $(t[29]=13.50, p<.001)$, and less enjoyable to watch $(t[29]=-7.66, p<.001)$ than the neutral 60 min film segment. These results are in line with those in Experiment 1 and as such again indicate successful manipulation of boredom through monotonous stimulation.

Figure 4 depicts the mean number of times the participants administered electrocutaneous shocks themselves (+SEM) while watching the $60 \mathrm{~min}$ film segment (boring or neutral). The primary analyses for Experiment 2 concerned testing the hypothesis that undergoing monotonous stimulation induces boredom and hence promotes the need to disrupt the monotony, even when that disruption comprises less than pleasant stimulation such as potentially painful electrical stimulation. In the first analysis we used the number of self-administered electrocutaneous stimuli as the dependent variable, hypothesizing that bored participants are more likely to self-administer shocks. This is exactly what was found. On average, participants shocked themselves 22.4 times when having

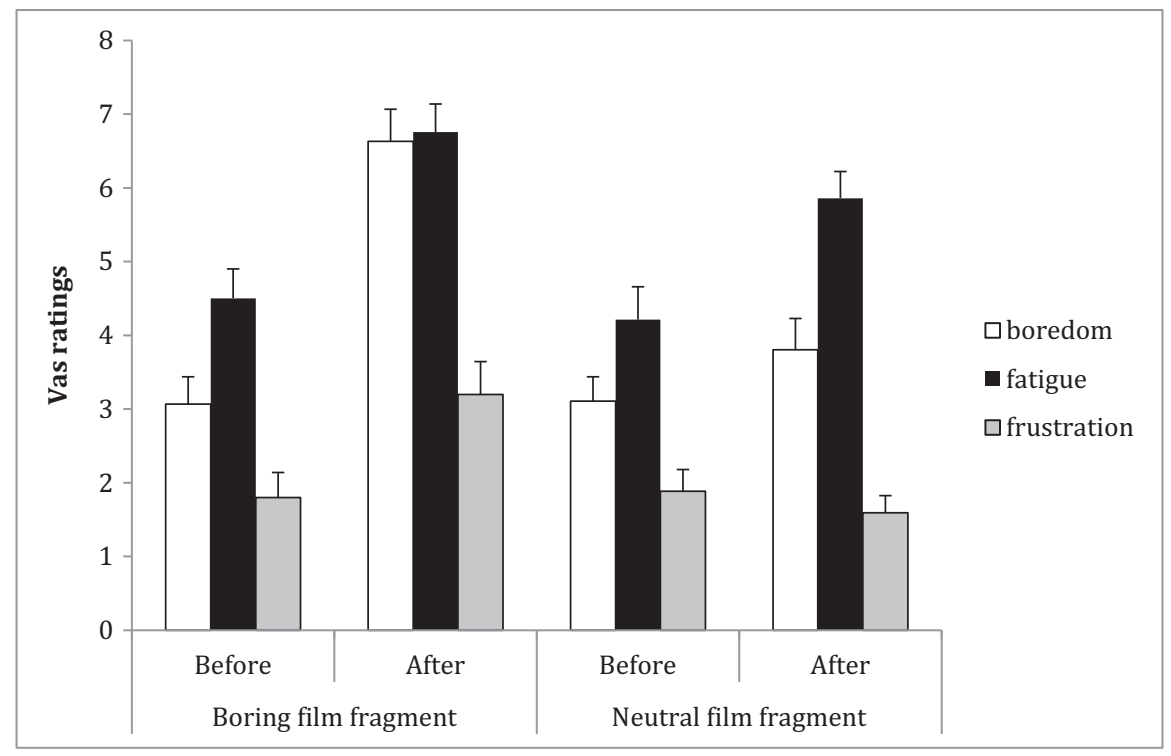

Fig. 3. Mean ratings of boredom, fatigue and frustration (+SEM) before and after viewing the boring versus neutral 60 min film segment of experiment 2 . 


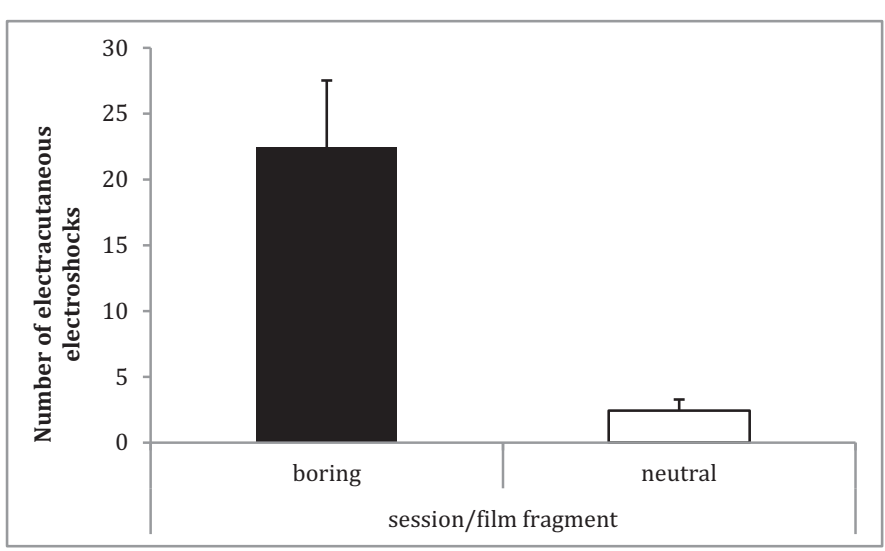

Fig. 4. The mean number of times the participants apply electroshocks (+SEM) while watching the $60 \mathrm{~min}$ boring versus neutral film segment.

to watch the monotonous film segment relative to 2.4 times when watching the non-monotonous film segment, $F(1,27)=18.99, p<.001$, $\eta^{2}$ partial $=.41$. Neither the covariate boredom proneness (i.e., the BPS score, $M=3.27, S D=.60$ ) nor sensation seeking (i.e., the SSS score, $M=2.97, S D=.54)$ interacted with Condition, both $F s<1$. These 2 covariates also did not significantly affect the frequency of selfadministering electroshocks, largest $F(1,27)=1.59$.

Clearly, boredom promotes the self-administration of electroshocks. Indeed, in the boring session, 28 of the 30 participants self administered electrocutaneous stimuli, whereas only 11 participants self-administered shocks when having to watch the nonmonotonous film segment. We further investigated whether the participants when bored would also self-administer more intense electrocutaneous stimuli by using the selected highest intensity throughout the procedure as the outcome variable. Here too, a main effect of Condition was found, $F(1,27)=46.45, p<.001, \eta^{2}$ partial $=.63$. The mean highest selected stimulus intensity when participants watched the boring film segment was $6.8 \mathrm{~mA}$ versus $2.0 \mathrm{~mA}$ when having to watch the neutral film segment.

\section{General discussion}

In the present study it was investigated whether boredom promotes eating and if so, whether this effect likely reflects an increased drive for satisfying rewarding stimulation or more plainly the drive to escape boredom. We found that an increased sense of boredom clearly promotes eating. Moreover, the finding that participants would even go so far as to self-administer electrical shocks strongly suggests that eating (or really doing anything) out of boredom arises from the drive to escape the tedium of monotonous stimulation. This is in line with recent research, in which it was shown that during a 15 min 'thinking period', in which people were left alone doing nothing, a substantial part of the participants voluntarily administered electroshocks (Wilson et al., 2014). Of course, when given the choice, one would probably rather eat chocolate than selfadminister shocks. In fact, we presented all participants $(n=60)$ from both experiments with this choice; that is, after their participation we asked them what option they would have chosen if we had given them the choice between self-administering shocks or eating chocolate M\&Ms during the two sessions. Nearly all participants $(\mathrm{n}=51,85 \%)$ indicated in hindsight that they would have preferred the M\&Ms to shocks.

The boredom effect did not appear to be moderated by boredom proneness or sensation seeking. This is somewhat surprising. The effect sizes of both covariates were very small, which indicates it is not just a matter of too little power caused by a small sample size.
It seems likely that other individual characteristics determine who will react more strongly to boredom with either increased eating or increased administration of electric shocks. Perhaps different coping styles in affect regulation play a role. In addition, it is possible that 'eating-out-of-boredom' is influenced by different individual characteristics than 'shocking-out-of-boredom' (e.g. restraint eating, emotional eating or BMI). Future research could focus on eating-specific individual characteristics and their possible influence on responding to boredom. In addition, future research might focus on the question whether, apart from intake, boredom affects food choice.

Although statistically significant, one might wonder what the real impact of the boredom manipulation is on eating behavior. What does it mean that on average participants in Experiment 1 ate $21.4 \mathrm{~g}$ of M\&Ms more when feeling bored? In terms of energy, this amounts to approximately $100 \mathrm{kcal}$ (or about $12 \mathrm{M} \& \mathrm{Ms}$; Froelich \& Stephenson, 2012) per hour. This would be trivial if most people rarely feel bored, but Eastwood et al. (2012) point out that in a 2003 survey among North-American youth $91 \%$ of the respondents reported experiencing boredom. In another 2009 British survey, respondents reported feeling bored on average for approximately 6 h per week (see Toohey, 2011).

The current results are also highly relevant for researchers studying emotional eating. Experiments on emotional eating typically involve a mood manipulation, which is compared to a neutral condition. If the neutral condition is actually perceived by the participants as boring, this might increase food intake in this supposedly neutral condition. This could reduce the contrast with the experimental condition. Boring control conditions might therefore obscure true effects of emotions on eating.

The present paradigm is potentially useful to study the propensity for non-suicidal self-injury (NSSI). In the present study, boredom proneness and sensation seeking were not related to self-inflicted pain, but perhaps participants with less effective coping styles or increased emotional reactivity are more inclined to revert to painful stimulation, in order to escape negative emotions (Chapman, Gratz, \& Brown, 2006). NNSI is a prevalent behavioral problem, related to psychopathology and suicide, and an experimental paradigm to study its causes and predictors, without relying on self-report, could prove a useful research tool.

To recapitulate, the present study demonstrates that boredom is a powerful emotional state motivating food consumption. Since the same situation also motivates self-administration of painful stimulation, this motivation likely reflects the drive to escape from or disrupt monotonous stimulation.

\section{References}

Abramson, E., \& Stinson, S. G. (1977). Boredom and eating in obese and non-obese individuals. Addictive Behaviors, 2, 181-185.

Britton, A., \& Shipley, M. J. (2010). Bored to death? International Journal of Epidemiology, 39, 370-371.

Chapman, A. L., Gratz, K. L., \& Brown, M. Z. (2006). Solving the puzzle of deliberate self-harm. The experiential avoidance model. Behaviour Research and Therapy, 44, 371-394.

Danckert, J. A., \& Allman, A.-A. (2005). Time flies when you're having fun. Temporal estimation and the experience of boredom. Brain and Cognition, 59(3), 236-245. doi:10.1016/j.bandc.2005.07.002.

Eastwood, J. D., Frischen, A., Fenske, M. J., \& Smilek, D. (2012). The unengaged mind. Defining boredom in terms of attention. Perspectives on Psychological Science, 7(5), 482-495. doi:10.1177/1745691612456044.

Farmer, R., \& Sundberg, N. (1986). Boredom proneness. The development and correlates of a new scale. Journal of Personality Assessment, 50, 4-17.

Feij, J. A., van Zuilen, R. W., \& Gazendam, A. (1982). De ontwikkeling van een Nederlandse vragenlijst voor sensation seeking. de Spanningsbehoeftelijst. [The development of a Dutch sensation seeking questionnaire. The Spanningsbehoeftelijst]. Gedrag: Tijdschrift voor Psychologie, 10, 364-383.

Froelich, A. G., \& Stephenson, W. R. (2012). How much do M\&M's weigh? Teaching Statistics, 35(1), 14-20.

Garg, N., Wansink, B., \& Inman, J. J. (2007). The influence of incidental affect on consumers' food intake. Journal of Marketing, 71, 194-206. 
Heatherton, T. F., \& Baumeister, R. F. (1991). Binge eating as escape from selfawareness. Psychological Bulletin, 110, 86-108.

Hill, A. B., \& Perkins, R. E. (1985). Towards a model of boredom. British Journal of Psychology, 76, 235-240.

Hill, A. J., Weaver, C. F., \& Blundell, J. E. (1991). Food craving, dietary restraint and mood. Appetite, 17(3), 187-197.

Koball, A. M., Meers, M. R., Storfer-Isser, A., Domoff, S. E., \& Musher-Eizenman, D. R. (2012). Eating when bored. Revision of the emotional eating scale with a focus on boredom. Health Psychology, 31, 521-524. doi:10.1037/a0025893.

Macht, M. (2008). How emotions affect eating. A five-way model. Appetite, 50, 1-11.

Macht, M., \& Dettmer, D. (2006). Everyday mood and emotions after eating a chocolate bar or an apple. Appetite, 46, 332-336.

Macht, M., \& Mueller, J. (2007). Immediate effects of chocolate on experimentally induced mood states. Appetite, 49, 667-674.

O'Hanlon, J. F. (1981). Boredom. Practical consequences and a theory. Acta Psychologica, 49, 53-82.

Seeger, P. (Producer/Director). (2008). In Search of Memory [Motion picture]. USA: Icarus Films.

Sommers, J., \& Vodanovich, S. J. (2000). Boredom proneness. Its relationship to psychological- and physical-health symptoms. Journal of Clinical Psychology, 56, 149-155.
Stickney, M. I., \& Miltenberger, R. G. (1999). Evaluating direct and indirect measures for the functional assessment of binge eating. International Journal of Eating Disorders, 26, 195-204.

Thackray, R. I. (1981). The stress of boredom and monotony. A consideration of the evidence. Psychosomatic Medicine, 43, 165-167.

Toohey, P. (2011). Boredom. A lively history. New Haven: Yale University Press.

Williamson, D. A., White, M. A., York-Crowe, E., \& Stewart, T. M. (2004). Cognitive-behavioral theories of eating disorders. Behavior Modification, 28, 711-738.

Wilson, T. D., Reinhard, D. A., Westgate, E. C., Gilbert, D. T., Ellerbeck, N., Hahn, C., et al. (2014). Just think. The challenges of the disengaged mind. Science, 345, $75-77$.

Zondag, H. (2007). Introductie van een Nederlandstalige schaal voor gevoeligheid voor verveling [Introduction of a Dutch language scale for boredom proneness]. Psychologie en Gezondheid, 35(5), 225-233. doi:10.1007/BF03071803.

Zuckerman, M. (2007). The Sensation Seeking Scale V (SSS-V). Still reliable and valid. Personality and Individual Differences, 43, 1303-1305. doi:10.1016/ j.paid.2007.03.021.

Zuckerman, M., Kolin, E. A., Price, L., \& Zoob, I. (1964). Development of a sensationseeking scale. Journal of Consulting Psychology, 28, 477-482. 